\title{
Parâmetros geomorfométricos do relevo no entendimento do nível de exposição dos sistemas cársticos na região limítrofe das bacias hidrográficas do Alto Iguaçu e do Alto Ribeira - Região norte de Curitiba - PR
}

\author{
Edenilson Roberto do Nascimento ${ }^{1}$, José Manoel dos Reis Neto ${ }^{2}$, \\ Antonio Manuel de Almeida Rebelo ${ }^{3}$, Tony Vinícius Moreira Sampaio 4 \& \\ Claudinei Taborda da Silveira ${ }^{4}$
}

\begin{abstract}
Resumo A região limite das bacias hidrográficas do Alto Rio Iguaçu e do Alto Rio Ribeira na Região Metropolitana de Curitiba limita dois compartimentos geomorfológicos com diferentes feições cársticas hospedadas em metadolomitos da Formação Capiru (Grupo Açungui). As feições endocársticas (cavernas e abismos) ocorrem somente na área pertencente à bacia hidrográfica do Rio Ribeira. As feições exocársticas (dolinas, poljes e uvalas) ocorrem nas duas bacias hidrográficas. O principal evento de carstificação regional relacionado à elaboração da Superfície Alto Iguaçu atingiu toda a área e proporcionou um mesmo ambiente geomorfológico até a abertura do Vale do Ribeira, no Mioceno Inferior, marcando um novo ciclo erosivo. A análise geomorfométrica foi utilizada com o objetivo de determinar as relações existentes entre a evolução geomorfológica e o nível de exposição dos sistemas cársticos. Os parâmetros geomorfométricos utilizados foram: Índice de Concentração da Rugosidade (ICR) do relevo, declividade e hipsometria. Foram abordadas as sub-bacias hidrográficas de Tranqueira (drenada pela bacia do Alto Rio Iguaçu) e as sub-bacias de Fervida e Bacaetava (drenadas pela bacia do Alto Rio Ribeira). Observou-se que os sistemas cársticos estão localizados na faixa altimétrica relacionada ao desenvolvimento da Superfície Alto Iguaçu, com mesma idade e desenvolvimento em um único ambiente climático e geológico. A análise geomorfométrica permite concluir que os diferentes níveis de exposição dos sistemas cársticos estão relacionados à erosão diferenciada dos metadolomitos da Bacia do Alto Ribeira em relação à Bacia do Alto Iguaçu. Tal fato explica a maior exposição dos sistemas cársticos nas áreas com relevo mais dissecado.
\end{abstract}

Palavras-chave: Feições cársticas, Parâmetros geomorfométricos, Região Metropolitana de Curitiba.

\begin{abstract}
Geomorphometric parameters of relief for understanding the exposure level of karst systems at the region between the Alto Rio Iguacu and Alto Rio Ribeira hydrographic basins - northern region of Curitiba, Parana State. The region between the Alto Rio Iguacu and Alto Rio Ribeira hydrographic basins, nearby the city of Curitiba, separate two geomorphological units with distinct karstic features in metadolomites of the Capiru Formation (Açungui Group - Precambrian). The endokarst features (caves and pits) are present only in the Rio Ribeira basin, whereas exokarstic features, such as dolines, poljes and uvalas, are present in both hydrographic basins. The main karstification event related to the Superfície Alto Iguaçu, has affected the whole area providing the same geomorphological environment, up to the open of the Ribeira River Valley during the Early Miocene making a new erosion cicle. We used geomorphometric analysis to determine the relationships between geomorphological evolution and the exposure level of the karstic systems. The used geomorphometric parameters were the relief Roughness Concentration Index (RCI), slope declivity and hypsometry. The studied area covers the following sub-basins: Tranqueira (drawn by the Alto Iguacu River; Fervida and Bacaetava (drawn by the Alto Ribeira River). The karst systems are localized in the altimetric zone related to the development of the Alto Iguaçu Surface, with the same age and in the same climatic and geological environment. The analysed geomorphometric parameters have allowed the conclusion that, the different exposure levels in the karst systems are related to the differential erosion of the metadolomites in the Alto Ribeira River Basin, when compared with the Alto Iguaçu River Basin. Thus this explains the greater exposure of the karst systems in those areas more dissected.
\end{abstract}

Keywords: Karst features, Geomorphometric parameters, Metropolitan Region of Curitiba.

1 - Programa de Pós-graduação em Geologia, Universidade Federal do Paraná, Curitiba (PR), Brasil. E-mail: deni_ern@ufpr.br

2 - Departamento de Geologia, Universidade Federal do Paraná, Curitiba (PR), Brasil. E-mail: jmreis@ufpr.br

3 - Pesquisador, Doutor em Geologia, Curitiba (PR), Brasil. E-mail: rebelo_antonio@hotmail.com

4 - Departamento de Geografia, Universidade Federal do Paraná, Curitiba (PR), Brasil. E-mail: tonysampaio@ufpr.br, claudineits@ufpr.br 
INTRODUÇÃO Apresenta-se os resultados da análise geomorfométrica do relevo no entendimento e caracterização dos diferentes níveis de exposição dos sistemas cársticos hospedados na Formação Capiru, do Grupo Açungui, ocorrentes na região norte de Curitiba-PR, na zona limítrofe das bacias hidrográficas do rio Iguaçu e Ribeira (Fig. 1).

Embora as feições cársticas da área estudada ocorram em um mesmo contexto geológico, observam-se diferenças no nível de exposição dos sistemas cársticos nas bacias hidrográficas do Alto Iguaçu (BAI) e do Alto Ribeira (BAR). Há presença de feições endocársticas (cavernas e abismos) somente na BAR, enquanto as feições exócarsticas (dolinas, poljes e uvalas) ocorrem na BAR e na BAI.

Para compreender a ocorrência de feições cársticas foram gerados e analisados os parâmetros geomorfométricos: declividade, hipsometria e Î́ndice de Concentração da Rugosidade do Relevo (ICR), na análise de três sub-bacias: 1) Tranqueira, drenada pela BAI; 2) Fervida e 3) Bacaetava, drenadas pela BAR. Assim, o objetivo do presente trabalho foi abordar a relação entre diferentes contextos hidrogeomorfológicos e a presença de diferentes níveis de exposição de sistemas cársticos (Fig. 2).

Além de estarem localizadas em um mesmo contexto geológico, com estruturas e litotipos semelhantes, as sub-bacias estudadas estão em um mesmo ambiente climático, pois a única não coalescente (Fervida) dista cerca de $3 \mathrm{~km}$ das demais sub-bacias estudadas.
Quanto à evolução geomorfológica regional, são identificados três eventos principais: a elaboração da Superfície do Purunã, cuja idade é do final do Cretáceo e início do Paleógeno; o surgimento da Superfície Alto Iguaçu, entre o Oligoceno e o Mioceno, e a abertura do Vale do rio Ribeira, a partir do Mioceno Inferior (Ab'Saber \& Bigarella 1961). É importante ressaltar, que apenas a sub-bacia de Tranqueira, drenada pela BAI, não foi afetada pela abertura do Vale do rio Ribeira, mantendo-se num sistema hidrogeomorfológico diferenciado das sub-bacias de Bacaetava e Fervida (Fig. 3).

Fiori et al. (1987), após inúmeras pesquisas nas áreas de ocorrência dos metassedimentos do Grupo Açungui, concluiu que estes foram afetados por três fases de deformação. Na primeira fase predominaram os cavalgamentos, caracterizados por dobras-falha, dobras e falhas de cavalgamento. A segunda caracterizou-se por dobramentos generalizados, com a geração de dobras abertas e fechadas, com eixo geral de dobramentos na direção NE-SW, e a terceira e última relacionada ao sistema de deslocamento transcorreste da Falha da Lancinha reativadas em condições rúpteis-dúcteis (Fig. 2).

A utilização da análise geomorfométrica adotada para a caracterização das diferentes feições cársticas, justifica-se, visto que a única diferença geológico-geomorfológica se dá pela existência de um diferente sistema hidrogeomorfológico, iniciado a partir do Mioceno Inferior, com a abertura do Vale do Ribeira.
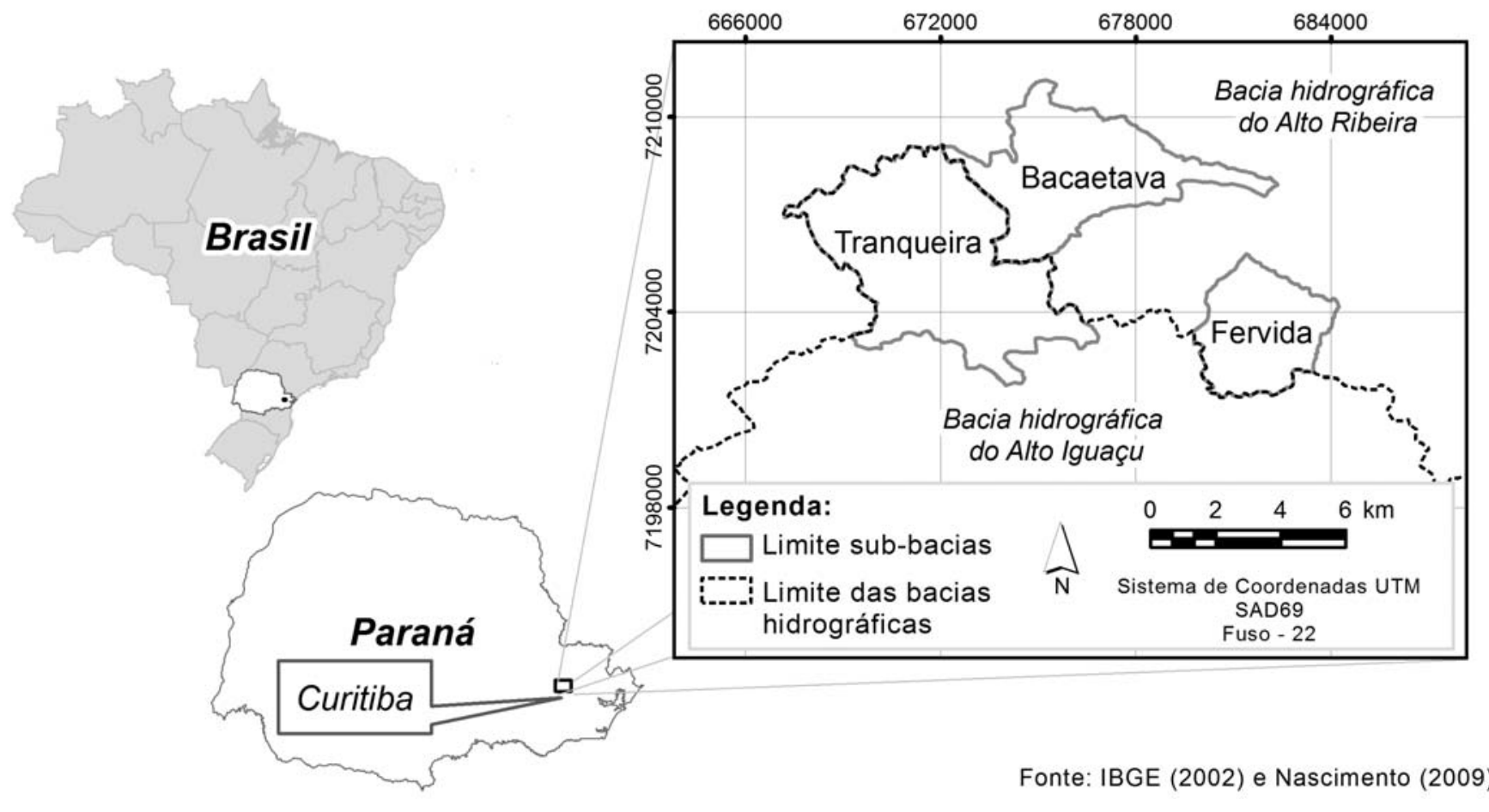

Figura 1 - Localização da área estudada. 


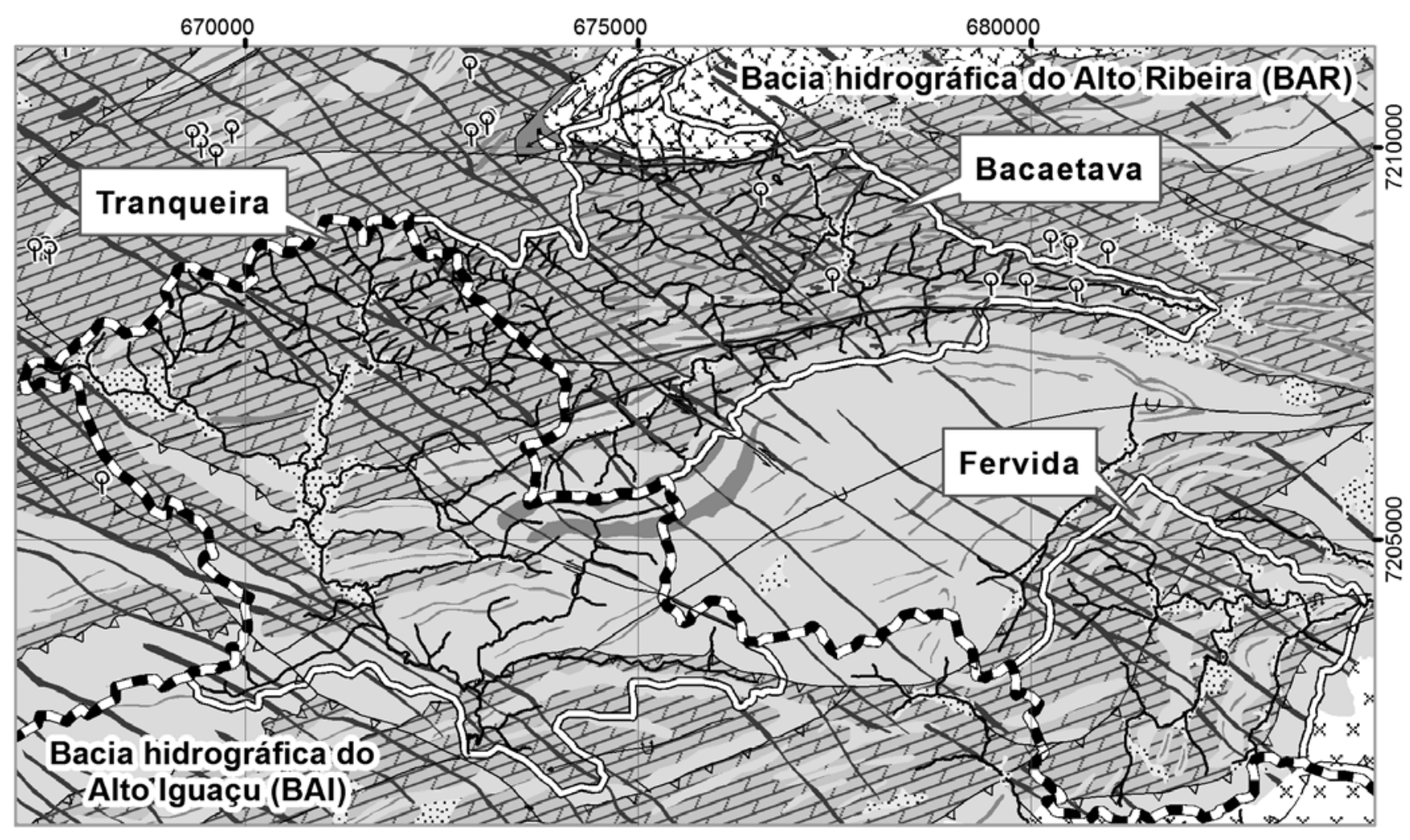

\section{Legenda:}

- Rios

드 Limite das bacias hidrográficas dos rios Iguaçu e Ribeira

$\square$ Limite sub-bacias

\section{Quaternário Holoceno}

Sedimentos recentes

$\therefore:$ Qha - Sedimentos de deposição fluvial (aluviões)

\section{Intrusivas básicas}

\section{Mesozoico}

JKd - Diques básicos

\section{Neoproterozoico - Cambriano}

\section{Grupo Setuva}

Formação Perau

$\mathrm{AF}^{2}>$ PMspx - Biotita-sericita xistos
Q Feições cársticas

(cavernas e abismos)

$0 \quad 10002000 \quad 3000 \mathrm{~m}$
Neoproterozoico

\section{Grupo Açungui}

Formação Capiru

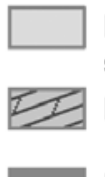

PSacm - Metassedimentos síltico-argilosos

PSacd - Mármores dolomíticos e metadolomitos

PSacq - Quartzitos, metarenitos e metarcósios

\section{Arqueano Paleoproterozoico}

Complexo Gnáissico-Migmatítico

$x \times$ APImge - Migmatitos

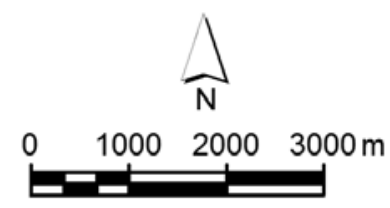

Estruturas geológicas

u- Dobras com indicação de caimento do eixo

$\Lambda$ Falha de cavalgamento

- - Falha indiscriminada

Falha transcorrente

Fonte: SANEPAR (2006)

Figura 2 - Geologia da área estudada.

Desse modo, foi assumido que as sub-bacias estudadas evoluíram em um mesmo ambiente hidrogeomorfológico e de carstificação até o Mioceno Inferior, a partir de quando a erosão remontante permitiu a entrada de um sistema erosivo diferenciado nas sub-bacias de Bacaetava e Fervida.

A explotação do aquífero carste para abastecimento hídrico de Curitiba e parte da Região
Metropolitana de Curitiba (RMC) e a atividade mineral para produção de corretivo agrícola e matéria prima para a construção civil, permite um amplo caráter exploratório das rochas carbonáticas da região, porém, o tipo de feições cársticas nelas ocorrentes pode limitar ou facilitar essa atividade. Áreas com exposição em zona vadosa de cavidades cársticas podem impedir a explotação de calcário, devido a incongruências com as 


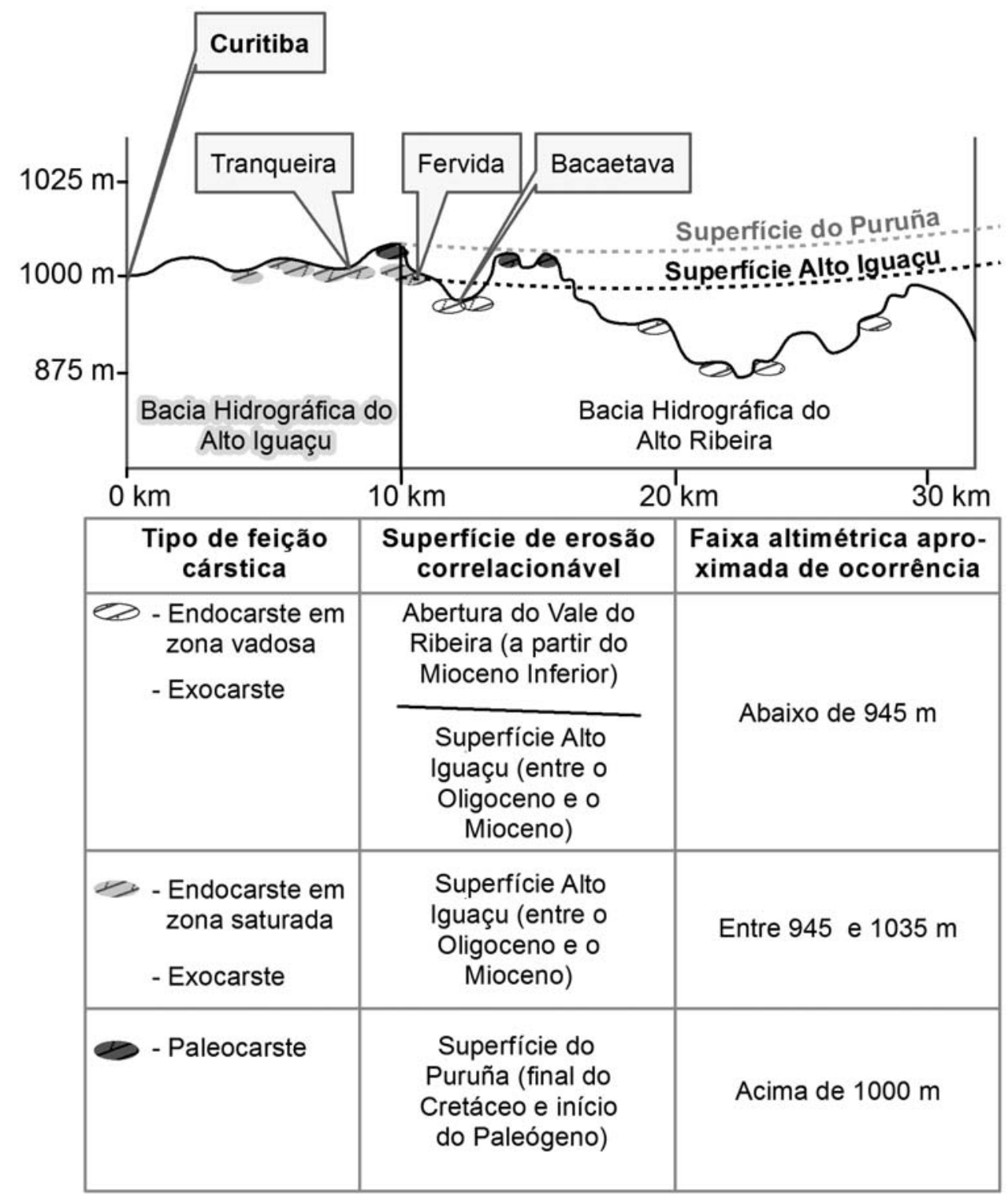

Figura 3 - Perfil esquemático mostrando a localização das sub-bacias estudadas, o tipo de feições cársticas ocorrentes e a paleosuperfície correlacionável (Nascimento et al. 2010).

leis ambientais. No entanto, a ocorrência de cavidades em zona saturada, pode torná-las excelentes sistemas aquíferos (Nascimento 2009).

Os estudos que abordaram o carste da RMC dedicaram-se principalmente ao estudo das características hidrogeológicas, geotécnicas e ambientais, visando a explotação do aquífero carste regional. Destacando-se Bonacim (1996), Lisboa (1997) e Hindi (1999), que descrevem e quantificam o modo de funcionamento do aquífero, e Silva \& Oka-Fiori (1996), que analisaram os traços gerais da geomorfologia, hidrografia e dos aspectos litoestruturais relacionados com as feições cársticas ocorrente no município de Almirante Tamandaré - PR.
A caracterização geomorfológica dessas áreas pode contribuir para o entendimento das características geográficas, geológicas e hidrogeológicas de regiões de ocorrência de ambientes cársticos, o que pode auxiliar na caracterização de áreas onde os metadolomitos podem ser explotados como minério (insumo agrícola, bem mineral para a indústria da construção civil entre outros), ou hospedeira de sistema aquífero e depósitos minerais, considerando a importância da preservação ambiental e do patrimônio espeleológico regional (Nascimento 2009).

MATERIAL E MÉTODO As sub-bacias objeto de estudo foram selecionadas a partir de cinco atributos 
geográficos, geológicos e geomorfológicos: (1) situação geográfica na zona limítrofe dos compartimentos geomorfológicos e hidrográficos drenados pelas BAI e BAR; (2) contexto geológico comum (Grupo Açungui e Formação Serra Geral); (3) contexto climático comum; (4) diferentes tipos de feições cársticas - endocársticas (cavernas) e exocársticas (dolinas, poljes, uvalas entre outros) com distintos graus de exposição e (5) evolução geomorfológica e cárstica comum até o Mioceno Inferior.

Como principais dados e informações foram utilizados os dados altimétricos e geológicos, disponibilizados pela Companhia de Saneamento do Paraná SA (SANEPAR), sobre o "Aquífero Carste", na escala 1:25.000. Foi também utilizado o Cadastro de Cavidades Naturais do Estado do Paraná, fornecido pelo Grupo de Estudos Espeleológicos do Paraná (GEEP-Açungui 2002).

Atualmente, um conjunto de novos métodos paramétricos tem sido empregado na modelização do relevo. A parametrização do relevo refere-se à representação quantitativa das características morfológicas da paisagem descritas de forma contínua, designada de geomorfometria (Wood 1996), consiste no processo de extração de atributos quantitativos do relevo de um Modelo Digital do Terreno (MDT), executado por meio de técnicas de modelagem digital, muitas vezes empregadas em Sistemas de Informações Geográficas (SIG), (Hengl 2003), que descreve as formas da superfície da Terra.

Os parâmetros geomorfométricos analisados foram calculados a partir de dados em estrutura raster, obtidos através da manipulação dos dados topográficos cedidos pela SANEPAR. A declividade de cada sub-bacia foi representada segundo as classes propostas pelo Instituto Brasileiro de Geografia e Estatística (IBGE 2007), na qual os valores inferiores a $3 \%$ representam relevo plano, entre 3 a $8 \%$ relevo suave ondulado, 8 a $20 \%$ relevo ondulado, 20 a $45 \%$ relevo forte ondulado, entre 45 a $75 \%$ relevo montanhoso e superior a $75 \%$ relevo escarpado.

A espacialização e quantificação dos intervalos hipsométricos seguiram a proposta de Strahler (1952), e objetivaram identificar remanescentes de paleosuperfícies e expressar em termos quantitativos o rebaixamento das sub-bacias hidrográficas, o qual possui relação direta com o funcionamento hidrológico intrínseco de cada bacia hidrográfica (Chorley \& Morley 1959). Os valores hipsométricos da área estudada foram discretizados em classes com intervalos de $20 \mathrm{~m}$. A separação das classes por sub-bacia permitiu a comparação da área ocupada por cada um dos intervalos entre elas.

Outro parâmetro geomorfométrico utilizado foi o Índice de Concentração da Rugosidade do Relevo (ICR) proposto por Sampaio (2009a), que se baseia no Índice de Rugosidade de Hobson (1972), o qual compara a medida de área real com a medida de área plana.

O uso do parâmetro geomorfométrico rugosidade é recorrente em estudos que abordam ambientes cársticos, Ferrari et al. (1998) ao caracterizar morfometricamente a superfície cárstica do Núcleo Cablocos no Vale do Ribeira, apontou o inconveniente da interação entre o número e a magnitude das irregularidades do terreno, que podem apresentar mesmo índice de rugosidade para terrenos com características diferentes. Karmann et al. (2000) e Sallun Filho \& Karmann (2007) ao caracterizarem respectivamente os planaltos da borda oriental da Chapada Diamantina e de Guapiara também utilizaram o índice de rugosidade para identificar as diferenças do relevo em suas áreas de estudo e também recorreram à classificação pontual da rugosidade para caracterizar o relevo cárstico.

Visando eliminar a classificação pontual do relevo e apoiado em valores similares ao proposto por Hobson (1972), Sampaio (2009b) propõe o uso do estimador de densidade por Kernel (Kernel estimation), que permite a análise da dispersão ou concentração espacial de processos espaciais de primeira ordem para fenômenos pontuais.

Os dados geomorfométricos obtidos com a utilização do ICR foram discretizados em cinco classes, obtidas pela separação de quartil, apoiado na proposta de Sampaio (2009a), cujas classes seguem resultantes são: muito baixa, baixa, média, alta e muito alta, conforme os respectivos intervalos: entre 1.607 a 9.340, 9.340 a $12.181,12.181$ a $14.549,14.549$ a 17.548 e 17.548 a 41.853.

A aplicação do estimador por Kernel e discretização igualitária do ICR foi realizada nos softwares do pacote ArcGis 10, e após a aplicação do estimador por Kernel e discretização os dados foram individualizados para as áreas de cada sub-bacia.

O cálculo da correlação espacial entre feições pontuais (cavernas) e zonais com atributos qualitativos/ ordenados (classes de ICR) baseou-se nos procedimentos desenvolvidos por Sampaio (2010), os quais foram obtidos a partir do emprego de ferramentas de Sistemas de Informações Geográficas (SIG) combinadas com técnicas de estatística clássica e de geoestatística.

Esses procedimentos adotam como fundamentação o princípio da isotropia, e adotam como premissa a concepção de que caso a distribuição de um evento pontual (caverna) ocorra de forma regular pelo espaço de análise, a quantidade observada para cada um dos elementos que compõem o evento/parâmetro zonal (classe de ICR) deverá ser proporcional à área ocupada pelos mesmos.

Caso o número de ocorrência de elementos pontuais não apresente proporcionalidade à área ocupada 
pelos elementos zonais, infere-se a presença de correlação numérica entre os mesmos (positiva ou negativa), podendo esta ser quantificada conforme a equação 1:

$$
R_{p z}=\left\{\left(n_{p z} / \sum p\right) /\left(s_{z} / \sum s\right)\right\}-1
$$

\section{Onde:}

$R_{p z}$ - correlação numérica entre o atributo pontual (qualitativo) e o zonal (qualitativo ou quantitativo ordenado - séries discretas), cujos valores variam de 0 a $>1$, sendo os valores maiores e menores que 0 indicativos de correlação positiva ou negativa, ou ainda, $R_{p z}$ - indica a quantidade de vezes que o fenômeno pontual ocorreu associado espacialmente ao zonal acima ou abaixo do esperado. O valor zero (0), ou próximo a este, indica que a quantidade de eventos pontuais se deu dentro do esperado para o elemento zonal em análise.

$n_{p z}$ - número de ocorrências do atributo pontual na área do elemento zonal cujo atributo se deseja analisar. Caso o elemento zonal se apresente espacialmente distribuído em mais de um polígono, $n_{p z}$ corresponderá ao somatório de ocorrências do elemento pontual nos mesmos.

$\sum p$ - somatório das ocorrências do elemento pontual na área total de estudo.

$s_{z}$ - área do polígono ou somatório das áreas dos polígonos cujo atributo se deseja analisar.

$\sum s$ - somatório das áreas de todos os polígonos da área de estudo ou área total de estudo.

Cabe observar que o uso do termo correlação espacial empregado no cálculo do $R_{p z}$ difere em formulação matemática da correlação utilizada pela estatística clássica, mas não em sentido conceitual, sendo também entendido como associação numérica entre duas variáveis e indica o grau de relacionamento linear entre as mesmas (Mingotti 2005).

A operacionalização do cálculo da correlação espacial entre elementos pontuais e zonais com atributos qualitativos foi dividida em duas etapas, sendo a primeira referente às operações com layers incluindo junção dos atributos (overlay: spatial join), cálculo das áreas dos polígonos do número de ocorrência de eventos pontuais por atributo zonal (summarize), e a segunda etapa relativa ao cálculo da correlação propriamente dito, sendo estes desenvolvidos em planilhas eletrônicas.

Os trabalhos de campo permitiram a coleta de dados topográficos e morfológicos das feições cársticas e a verificação dos resultados obtidos no geoprocessamento e modelagens.

RESULTADOS E DISCUSSÃO

Os principais resultados obtidos pela análise digital do relevo permitiram observar diferenças geomorfológicas nas sub-bacias estudadas, essas diferenças decorrem principalmente da ação dos sistemas erosivos da BAI e da BAR e da disposição litológica da Formação Capiru marcada por grandes estruturas geológicas dúcteis, rúpteis e dúcteis-rúpteis.

Enquanto nas sub-bacias hidrográficas de Tranqueira e Fervida cerca de 30\% da área apresentam relevo plano e suave ondulado, com declividades inferiores a $8 \%$, a sub-bacia de Bacaetava apresenta apenas $18 \%$ de sua área abaixo de $8 \%$ de declividade. Os intervalos que expressam relevos ondulados até forte ondulados entre 8 e $45 \%$ aumentam respectivamente; $62 \%$ da área da sub-bacia de Tranqueira, $67,5 \%$ da área da sub-bacia de Fervida e $72,5 \%$ da área de Bacaetava. Os relevos classificados como montanhosos até escarpados, com declividades superiores a $45 \%$, ocorrem em $5,4 \%$ da área da sub-bacia de Tranqueira, 2\% da área de Fervida e 9,3\% da área de Bacaetava (Fig. 4).

A variabilidade dos dados altimétricos mostram semelhanças entre as sub-bacias de Tranqueira e Fervida, onde os valores de desvio padrão encontrados são, respectivamente, 35 e $25 \mathrm{~m}$, bem abaixo do encontrado para a sub-bacia de Bacaetava, de $52 \mathrm{~m}$. A faixa altimétrica preferencial de ocorrência das feições endocársticas e exocársticas entre, aproximadamente, 920 e $1.040 \mathrm{~m}$, é próxima à faixa de ocorrência de carstes correlatos à evolução da Superfície Alto Iguaçu, descritos por Rebelo et al. (2002) entre 945-1.035 m, o que corrobora a hipótese de um contexto geológico, climático e geomorfológico comum de carstificação nas três sub-bacias. As cotas altimétricas máximas, acima de 1.100 m de altitude, são encontradas nas bacias de Tranqueira e Bacaetava na área de ocorrência da falha de cavalgamento de Morro Grande. A sub-bacia de Fervida, com relevo mais plano, tem suas altitudes mais elevadas em 1.075 m, também em área de ocorrência de falhas de cavalgamento (Figs. 4 e 5).

Somente na sub-bacia de Bacaetava as cotas mínimas estão abaixo de $915 \mathrm{~m}$ de altitude, com drenagens truncando o maciço metadolomítico. Chama à atenção a existência de três das cinco cavernas existentes na porção mais a jusante desta sub-bacia hidrográfica, onde ocorrem diques de diabásio com espessura e contiguidade incipiente e cristas quartizíticas paralelas às drenagens. As outras duas cavernas estão próximas aos diques de diabásio que formam o primeiro nível de base local, que auxilia no barramento da incisão vertical das drenagens (Fig. 2).

Embora o contexto geológico seja o mesmo, pode-se verificar que os controles litológicos que atuam na escala de sub-bacias condicionam um relevo relativamente mais plano nas sub-bacias dos rios Fervida e Tranqueira em relação à sub-bacia de Bacaetava. Esses níveis de base locais são determinados 


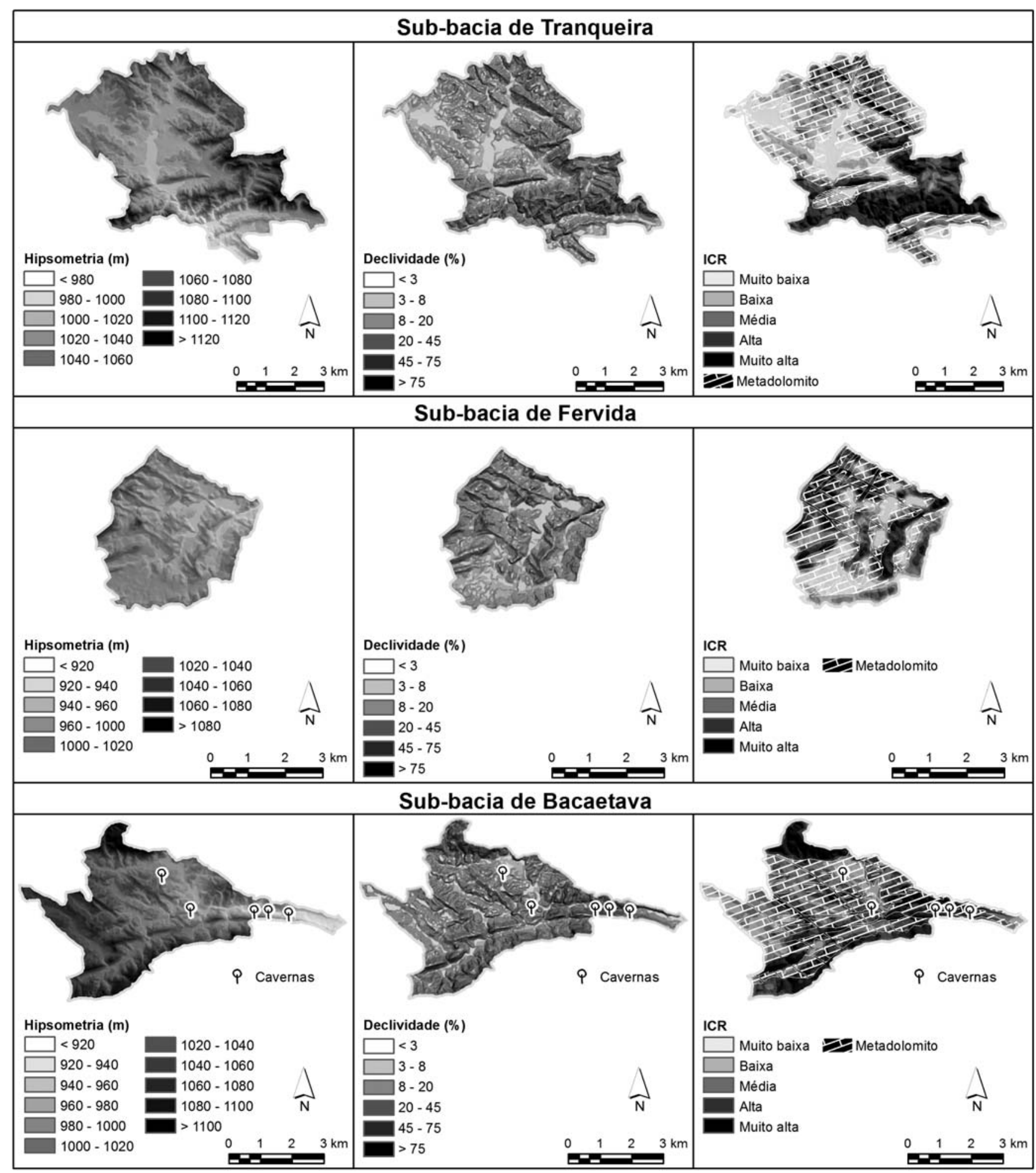

Figura 4 - Hipsometria, declividade e ICR das sub-bacias estudadas.

principalmente por faixas de rochas metassedimentares e diques de diabásio.

Na sub-bacia de Tranqueira os diques de diabásio quando intrudidos em metadolomitos são transpostos pelas drenagens na direção próxima N-S, porém quando intrudidos em metassedimentos, normalmente constituem vales onde os rios se encaixam, possibilitando a transposição das faixas metassedimentares pelas drenagens. Já as falhas de cavalgamento de direção próxima E-W e NE também são transpostas pelas drenagens na direção próxima N-S que, assim como os diques de diabásio, funcionam como níveis de base locais.

Na sub-bacia de Fervida os diques de diabásio são bastante recorrentes e figuram como a principal 


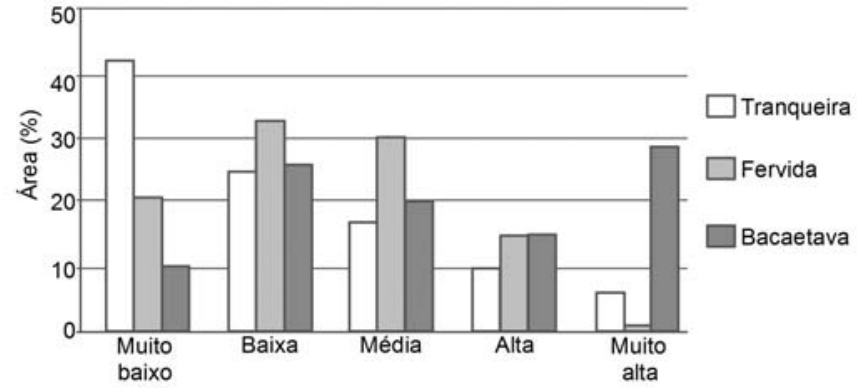

Figura 5 - Distribuição das classes de ICR nas sub-bacias.

componente da conformação geomorfológica local, pois dependendo do litotipo encaixante apresentam-se como cristas ou vales alongados de direção NW (Hindi 1999). Nesta sub-bacia há forte controle dos níveis de base locais, pois as drenagens aproveitam as descontinuidades de direção NE para transpor os diques de diabásio que funcionam como níveis de base locais (Fig. 2).

As faixas hipsométricas das três sub-bacias expressam numericamente um relevo esculpido com grande influência da disposição litológica em relação às drenagens, sendo o maciço metadolomítico mais preservado quando há a presença de níveis de base locais. Por conseguinte, os sistemas cársticos são mais ou menos expostos em ambiente vadoso dependendo da existência ou não de níveis de base locais que preservem o maciço metadolomítico que o hospeda.

Com o objetivo de caracterizar o relevo e sua relação com a forma de ocorrência das feições cársticas, os dados geomorfométricos ICR discretizados são apresentados na figura 5, onde se observa as características do relevo de cada sub-bacia.

A sub-bacia de Tranqueira apresenta ICR predominantemente entre baixo e médio, e possui sistemas cársticos em relativo equilíbrio com a paisagem, com feições exocársticas em posição vadosa e endocársticas em posição freática, condições propícias para a formação de aquífero cárstico.

Já na sub-bacia de Fervida, onde os valores de ICR predominam entre baixa e alta rugosidade, coexistem feições exocársticas, exposições de condutos cársticos (protocavernas) e feições endocársticas em zona saturada. Chama atenção a presença de fontes cársticas surgentes, conhecidas com "fervidas", em alusão às águas que "fervem" do chão e agitam o sedimento (Hindi 1999). O nome Fervida, como é conhecida a região onde ocorre essa sub-bacia, deriva das diversas fontes cárstica existentes. Conforme Nascimento (2009) a sub-bacia de Fervida possui um relevo intermediário em relação à Tranqueira e Bacaetava, isso se deve a uma captura recente desta sub-bacia para o sistema hidrográfico da bacia hidrográfica do Alto Ribeira, o que provoca o rejuvenescimento do relevo e truncamento dos metadolomitos que hospedam o sistema aquífero. Este momentum da evolução do relevo permite a exposição de condutos (protocavernas), o que explica a grande ocorrência de fontes cársticas, o esvaziamento paulatino do sistema aquífero e o encaminhamento para a abertura de cavernas (Fig. 4).

Na sub-bacia de Bacaetava destaca-se nos metadolomitos o valor de ICR de alta e muito alta rugosidade, principalmente próximo à sua foz, onde se encontra o principal adensamento de cavernas (três das cinco cavernas ocorrentes). A presença de sistemas cársticos em zona vadosa, que preteritamente se encontravam em posição freática e a existência de salões em diferentes níveis, refletem uma fase de rejuvenescimento do relevo acelerando os processos erosivos, o que ocasiona a instabilização geotécnica dos condutos cársticos e o abatimento de cavernas (Nascimento 2010).

O gráfico da figura 6 apresenta a correlação espacial por sobreposição para o atributo caverna e seu intervalo de ocorrência de ICR. No gráfico fica evidente a correlação inversa entre ICR muito baixa, baixa e média com a existência de cavernas, e a correlação direta com ICR alta a muito alta. Esse fato corrobora a relação entre evolução do relevo e o nível de exposição dos sistemas cársticos.

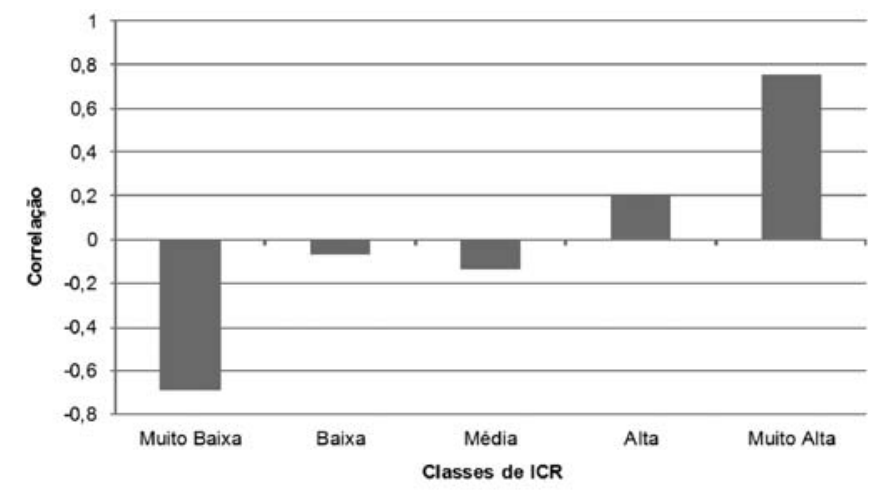

Figura 6 - Valores de correlação espacial $\left(R_{p 2}\right)$ entre cavernas e classes de ICR.

\section{CONCLUSÕES}

1) A evolução geomorfológica cenozoica do leste paranaense, após a abertura do vale do rio Ribeira, é responsável pela captura de bacias hidrográficas outrora drenadas pela BAI situada na área de estudo. O regime erosivo mais acentuado provoca o rejuvenescimento do relevo, fato que permite o truncamento e exposição dos sistemas cársticos. 
2) Em escala de sub-bacias os controles litoestruturais constituídos principalmente por faixas metassedimentares e diques de diabásio funcionam como níveis de base locais, preservando o maciço metadolomítico da incisão vertical das drenagens. No entanto, a preservação dos maciços metadolomíticos é eficiente somente quando as drenagens possuem seus cursos perpendiculares aos níveis de base locais, já quando os cursos são paralelos à rocha ou à estrutura geológica que condiciona os níveis de base locais, ocorre o favorecimento do entalhe dos canais sobre os metadolomitos e a exposição mais pronunciada dos sistemas cársticos.

3) Com a análise geomorfométrica do relevo na escala de sub-bacias foram identificados, considerando as características de declividade, hipsométricas e ICR, três estágios erosivos do relevo, aos quais estão associados sistemas cársticos com diferentes graus de exposição, organização espacial e forma nas sub-bacias estudadas, são eles: a) na sub-bacia de Tranqueira, a única drenada pela BAI, onde se verificou um relativo “equilíbrio" entre a erosão e as superfícies de aplainamento estabelecidas regionalmente, o que permite que os sistemas cársticos estejam em equilíbrio com a paisagem, com feições exocársticas em posição vadosa e endocársticas em posição freática, condições propícias para a formação de aquífero cárstico; b) na sub-bacia de Fervida, onde coexistem feições exocársticas, exposições de condutos cársticos (protocavernas) e feições endocársticas em zona saturada, fato diretamente ligado à captura recente dessa sub-bacia pelo sistema hidrográfico do rio Ribeira, nesse estágio o aquífero cárstico está sendo exposto e inicia-se a abertura das protocavernas; c) na sub-bacia do rio Bacaetava, onde há exposição em zona vadosa do endocarste que preteritamente se encontrava em posição freática, principalmente no baixo e médio curso, permite a existência de salões em diferentes níveis, desconectados da rede hidrográfica atual. Essas condições refletem um novo ciclo erosivo vinculado à abertura do vale do rio Ribeira.

4) O cálculo da correlação espacial numérica $\left(R_{p z}\right)$ entre cavernas e classes de ICR apontou para uma relação direta entre o aumento da rugosidade e a ocorrência de cavernas. Foram encontrados os valores de $-0,69$ para a classe de menor rugosidade, $-0,07$ para classe de baixa rugosidade, $-0,13$ para classe de média rugosidade, 0,21 para a classe de rugosidade alta e 0,75 para a classe de rugosidade muito alta. Os valores próximo a 1 , verificados nas classes de alta e muito alta rugosidade, indicam correlação positiva entre essas classes de rugosidade e a ocorrência de cavernas, já os valores negativos verificados em todas as demais classes de relevo indicam a ocorrência de cavernas abaixo do esperado nessas classes. O ICR aplicado nas áreas de ocorrência de rochas carbonáticas, mostrou-se um importante parâmetro geomorfométrico na caracterização dos diferentes estágios erosivos do relevo e os diferentes níveis de exposição dos sistemas cársticos.

5) Para a exploração mineral das áreas carbonáticas com carstificação correlata a elaboração da Paleosuperfície do Alto Iguaçu na RMC, recomenda-se o zoneamento a partir do estudo das características geomorfológicas regionais, pois deste modo, pode-se classificar áreas propicias à exploração de metadolomitos como minério ou como hospedeiros de sistemas aquíferos. Para tanto, sugere-se a utilização do ICR proposto por Sampaio (2009), que neste estudo mostrou-se eficaz na sintetização das características geológicas e geomorfológicas que determinam o grau de exposição dos sistemas cársticos, além de ser um método de fácil utilização em ambiente SIG. A figura 7 modela com base no ICR do relevo, o tipo de exploração mais adequada para cada sub-bacia estudada.

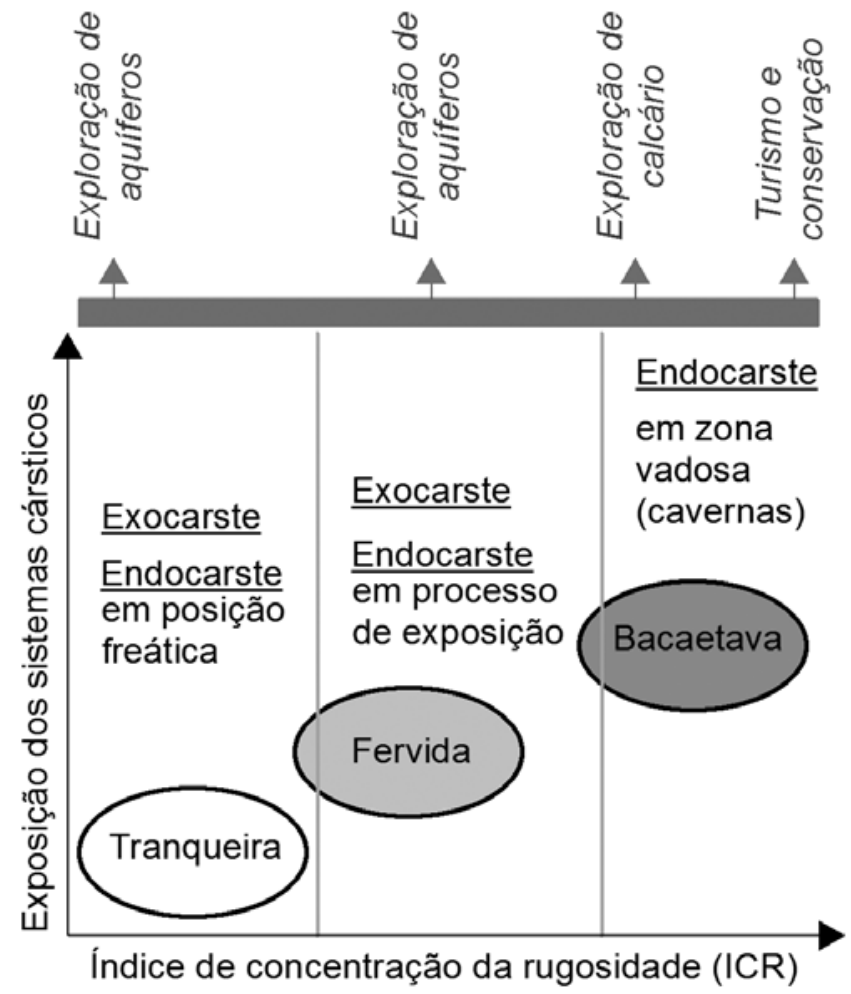

Figura 7 - Modelo demonstrando o tipo de exploração mais adequado para o carste das sub-bacias estudadas em função dos diferentes níveis de exposição dos sistemas cársticos (Nascimento 2009).

Agradecimentos Ao LAMIR (Laboratório de Análise de Minerais e Rochas do Departamento de Geologia da UFPR), ao Programa de Pós-graduação em Geologia da UFPR, a PETROBRAS pelo financiamento. 


\section{Referências}

Ab’Saber A.N. \& Bigarella J.J. 1961. Considerações sobre a geomorfogênese da serra do Mar no Paraná. Boletim Paranaense de Geografia, 4/5:94-110.

Bonacim E. 1996. Dinâmica do Sistema Hidrogeológico Cárstico na Área de Tranqueira - Região Metropolitana de Curitiba. Dissertação de Mestrado, Setor de Ciências da Terra, Universidade Federal do Paraná, Curitiba, 162 p.

Chorley R.J. \& Morley L.S.D.A. 1959. Simplified approximation for the hipsometric integral. Journal of Geology, 67:566-571.

Ferrari J.A., Himura S.T., Karmann I. 1998. Caracterização Morfométrica de uma Superfície Cárstica do Vale do Ribeira, São Paulo (Núcleo Cablocos - PETAR). Revista do Instituto Geológico, 19:9-17.

Fiori A.P., Reis Neto J.M., Monastier M.S., Camargo E.C., Fumagalli C.E., Salamuni E., Lima J.P.S., Moro R.P.X., Kops P.T. 1987. Aspectos Estruturais e Estratigráficos do Grupo Açungui e da Formação Itaiacoca no Estado do Paraná. Curitiba, UFPR-MINEROPAR, 191 p.

GEEP-Açungui - Grupo de Estudos Espeleológicos do Paraná. 2002. Cadastro das Cavidades Naturais do Estado do Paraná. Luis Fernando Silva da Rocha (org.). Formato shapefile.

Hengl T. 2003. Pedometric mapping: bridging the gaps between conventional and pedometric approaches. $\mathrm{PhD}$ Thesis, Wageningen University, Enschede, 233 p. Disponível em: http://spatial-analyst.net/wiki/index. php?title=Pedometric_mapping:_PhD_thesis. Acessado em: 07/03/2010.

Hindi E.C. 1999. Caracterização Hidroquímica e Hidrogeológica das Fontes Cársticas das Bacias dos Rios Tumiri, Água Comprida, Fervida e das Onças - Colombo, PR. Dissertação de Mestrado, Setor de Ciências da Terra, Universidade Federal do Paraná, Curitiba, 122 p.

Hobson R.D. 1972. Surface roughness in topography: quantitative approach. In: Chorley R.J. (ed.) Spatial analysis in geomorphology. New York, Harper and Row, p. 225-245.

IBGE - Instituto Brasileiro de Geografia e Estatística. 2002. Malha Municipal digital do Brasil (escala 1:50.000). Disponível em: ftp://geoftp.ibge.gov.br/mapas/topograficos/topo50/shp/. Acessado em: 04/10/2007.

IBGE - Instituto Brasileiro de Geografia e Estatística. 2007. Manual Técnico de Pedologia - $2^{a}$ edição. Rio de Janeiro, IBGE, Manual Técnico 4, 316 p.

Karmann I., Pereira R.G.F.A., Mendes L.F. 2000. Caverna do Poço Encantado, Chapada Diamantina, Bahia: patrimônio geológico e biológico. In: Schobbenhaus C., Campos D.A., Queiroz E.T., Winge M., Berbert-Born M. (eds.) Sítios Geológicos e Paleontológicos do Brasil. Disponível em: http://www.unb.br/ig/sigep/sitio091/sitio091. htm. Acessado em: 03/12/2010.

Lisboa A.A. 1997. Proposta de metodologia para avaliação hidrogeológica do Aquífero Cárstico, Compartimento de São Miguel. Dissertação de Mestrado, Setor de Ciências da Terra, Universidade Federal do Paraná, Curitiba, 127 p.

Mingotti S.A. 2005. Análise de dados através de métodos de estatística multivariada: uma abordagem aplicada. Belo Horizonte, Editora UFMG, 297 p.
Nascimento E.R. 2009. Caracterização de feições cársticas a partir de parâmetros morfométricos do relevo: Região Metropolitana de Curitiba (RMC). Dissertação de Mestrado, Setor de Ciências da Terra, Universidade Federal do Paraná, Curitiba, 103 p.

Nascimento E.R., Reis Neto J.M., Rebelo A.M.A. 2010. Aplicação do índice de concentração da rugosidade do relevo no entendimento do nível de exposição dos sistemas cársticos ocorrentes na região norte do município de Curitiba, PR. Revista Brasileira de Geomorfologia, 11(2):61-68.

Rebelo A.M.A, Reis Neto J.M., Guimarães S.B. 2002. Controles Geomorfológicos na Gênese das Cavernas em Calcários na Bacia Açungui-Ribeira - Estado do Paraná. In: SBG, Congresso Brasileiro de Geologia, 41, Anais, p. 699.

Sallun Filho W. \& Karmann I. 2007. Dolinas em arenitos da Bacia do Paraná: evidências de carste subjacente em Jardim (MS) e Ponta Grossa (PR). Revista Brasileira de Geociências, 37(3):551-564.

Sampaio T.V.M. 2009a. Parâmetros morfométricos para Mapeamento da rede de rios - uma proposta baseada na análise da Bacia Hidrográfica do Rio Benevente - ES. Tese de Doutorado, Instituto de Geociências, Universidade Federal de Minas Gerais, Belo Horizonte, 120 p.

Sampaio T.V.M. 2009b. Índice de Concentração Da Rugosidade (ICR): uma proposta para o mapeamento morfométrico via emprego de Geotecnologias. Disponível em: http://www.geo.ufv.br/simposio/simposio/trabalhos/trabalhos_completos/eixo1/094.pdf. Acessado em: 23/05/2009.

Sampaio T.V.M. 2010. Álgebra de mapas e correlação espacial entre feições pontuais e zonais com atributos qualitativos - uma análise a partir da correlação entre a distribuição espacial das nascentes e litotipos da Bacia Hidrográfica do Rio Benevente - ES. In: ABGE/ CTCGG, Simpósio Brasileiro de Cartografia Geotécnica e Geoambiental, 7, Anais, p. 1-11.

SANEPAR - Companhia de Saneamento do Paraná SA. 2006. Fornecimento de dados sobre o "Aqüifero Carste da Região Metropolitana de Curitiba”. Curitiba, mapa geológico e de relevo, escala 1:25.000.

Silva R. \& Oka-Fiori C. 1996. Estudo das formas cársticas como base para o gerenciamento do uso do manancial subterrâneo na região de Almirante Tamandaré e Rio Branco do Sul - PR. Boletim Paranaense de Geociências, 44:59-66.

Strahler A.N. 1952. Hypsometric (Areal-Atitude) analyses of erosion topography. Bulletin Geological Society of America. Boulder, 63:1117-1142.

Wood J. 1996. The geomorphological characterisation of digital elevation models. PhD Thesis, University of Leicester, Leicester, 185 p. Disponível em: http://www. soi.city.ac.uk/ jwo/phd. Acessado em: 12/08/2009.

\section{Manuscrito ID 24584 Submetido em 06 de outubro de 2011 Aceito em 07 de fevereiro de 2012}

